\title{
The Efficacy of Aqueous False Yam (Icacina Oliviformis) Tuber Extract Against Cowpea Aphids (Aphis Craccivora Koch)
}

\author{
Theophilus Yaw Alale ${ }^{1 *}$, Nelson Opoku ${ }^{1}$, Charles Adarkwah ${ }^{2}$
}

Cowpea aphids (Aphis craccivora) are a major pest of cowpeas (Vigna unguiculata), which feed on the plant at the vegetative stage by sucking the sap. In an endeavour to find an new method of controlling aphid infestation in the Northern Ghana, an in vitro study was carried out to investigate the effect of different concentrations of aqueous false yam (Icacina oliviformis) tuber extract against cowpea black aphids (Aphis craccivora Koch). It was observed that a 55\% dilution was as effective as undiluted extract after 72 hours of exposure. However, mortality was significantly affected $(p<0.05)$ with respective least significant differences (LSD's) values of 0.63 and 0.75 , by soaking periods, concentration, and duration of exposure when extract was applied topically to the aphids as well as the soaked leaf, indicating that the most plausible mode of action of the false yam tuber extract would be toxic by direct contact and through feeding. The effectiveness of this study may help poor farmers save the cost of chemical pesticides and prevent their hazardous impact on the environment.

\section{INTRODUCTION}

Cowpea (Vigna unguiculata) is a grain legume grown widely in the tropics and the subtropics. It has been used as the primary substitute for a protein source in many urban and rural homes in Nigeria, Niger, Burkina Faso, Myanmar, Cameroon and Mali (Ishiyaku et al., 2010). However, the crop is subject to significant loss or complete failure due to severe pest infestation (Singh \& Emdam, 1979). Some of these insect pests may include Aphis craccivora, Maruca vitrata, Megalurothrips sjostedti and Callosobrucus maculates. It is estimated that the average yield for monoculture crop is about $1500 \mathrm{~kg} / \mathrm{ha}$ in the United States, $6500 \mathrm{~kg} / \mathrm{ha}$ in South America and Asia but often below $400 \mathrm{~kg} /$ ha in Nigeria and other growing African countries (Singh, 1986). In spite of the extensive production and the significance of cowpea in Africa, yield per hectare is relatively low (Ofuya, 1997). This has been attributed mainly to the severe infestation and losses caused by various insect pests in the field and during storage (Jackai \& Daoust, 1986).

Cowpea aphids (Aphididae: Hemiptera) are predominant class of insect pest with global distribution. Aphids attack about 50 crops in 19 plant families due to their high association with host plants in the family Leguminosae (Radha, 2013).

The promising option to farmers in controlling these pests was the indiscriminate use of chemical agro-pesticides (Shannag, Capinera, \& Freihat, 2014). This phenomenon has led to the eradication of

\footnotetext{
${ }^{1}$ Department of Biotechnology, University for Development Studies, P.O.Box TL, 1882, Tamale Ghana.

${ }^{2}$ Department of Agronomy, University for Development Studies, P.O.Box TL, 1882, Tamale Ghana.
} *To whom correspondence should be addressed:
tyalale@ymail.com

Except where otherwise noted, this work is licensed under https://creativecommons.org/licenses/by/4.0/ doi: $10.22186 / j y i .32 .4 .22-24$ beneficial insect species, which is a threat to human health and environmental hazards. This calls for the search and use of environmentally friendly biopesticides instead of conventional pesticides to control aphid's outbreak (Leake, 2000). False yam tuber (Icacina oliviformis) extract has been shown to have some toxic compounds that need to be investigated to find its effect on cowpea aphid. Its effect on aphids has been attributed to the presence of inhibitory factors (resins) which make sap unpleasant to feed on (Dei, Bacho, Adeti, \& Rose, 2011). The false yam plant's year-round availability makes it economically affordable to be used as a substitute biopesticide for the conventional pesticides. This study investigates the efficacy of aqueous false yam tuber extract used as a biopesticide as an alternative for chemical pesticides against cowpea aphids.

\section{MATERIALS AND METHODS}

\section{Sourcing and Processing of False Yam}

The false yam tubers were obtained from the wild within the environments of the Nyankpala campus of the University for Development Studies, Tamale, Ghana. The tubers were then manually dug with a hoe and a cutlass before processing.

The dug tubers were peeled and chopped into pieces of about $2 \mathrm{~cm}$ with a cutlass and washed to remove any soil particles and dirt. The treatments were prepared by soaking $2.5 \mathrm{~kg}$ of chopped tubers in water for 48 hours, 72 hours and 96 hours in order to obtain varying concentrations. After the respective periods of soaking, the preparation was decanted to obtain the solution.

\section{Insect Culture}

A stock culture of $A$. craccivora was maintained on cowpea under laboratory conditions at room temperature and $70.0 \pm 5.0 \%$ relative humidity (RH) and a photoperiod of 16 hours of light: 8 hours of dark (L16:D8) for several generations. In all experiments, the insects were put on fresh cowpea plants cultivated in small plots and enclosed individually in netted cloth, the tops of which were covered 
with muslin held in place with rubber bands.

\section{Toxicity and Mortality Test - Leaf Soaking}

Cowpea leaves were soaked in $15-20 \mathrm{mls}$ of test solution for $1 \mathrm{~min}$. The leaves were removed and allowed to dry for $1 \mathrm{hr}$. Fifteen aphids (3-14 day old) were then released to feed on the leaves. The leaves together with the aphids were transferred into plane/transparent bottle containers and covered with muslin cloth to allow air circulation. Five different concentrations were used and each was replicated three times. Adult mortality was calculated after 24, 48 and 72 hours of exposure.

\section{Contact Toxicity By Topical Application}

Tests for contact toxicity by topical application were carried out in the laboratory at room temperature, $65-70 \% \mathrm{RH}$ and under an L16:D8 photo-regime. Three- to fourteen-day-old adult aphids of mixed sex were transferred into glass Petri dishes $(7.0 \mathrm{~cm}$ diameter) lined with moist filter paper to keep the aphids immobile. The immobilized insects were picked individually and $10 \mu \mathrm{l}$ of each diluted false yam tuber extract was applied to the dorsal surface of the abdomen of each using a micro-pipette applicator. Thirty adults in three replicates of 10 insects each were treated with false yam tuber extract preparation. Water only was used as a control. After treatment, the adults were transferred into glass Petri dishes (10 insects/Petri dish) containing fresh cowpea leaves to serve as food. Insect mortality was recorded at 24, 48 and 72 hours after treatment.

\section{RESULTS}

Mortality was significantly affected at $p=0.023$ by soaking periods, concentration, and duration of exposure (Figure 1). Aphid mortality increased with increasing concentration of false yam tuber extract except at $70 \%$ concentration, where a decrease in mortality was observed, after which mortality rate increased again with increasing concentration. It is of interest to note that $55 \%$ concentration was as effective as $100 \%$ concentration (zero dilution) and this was true for all soaking periods.

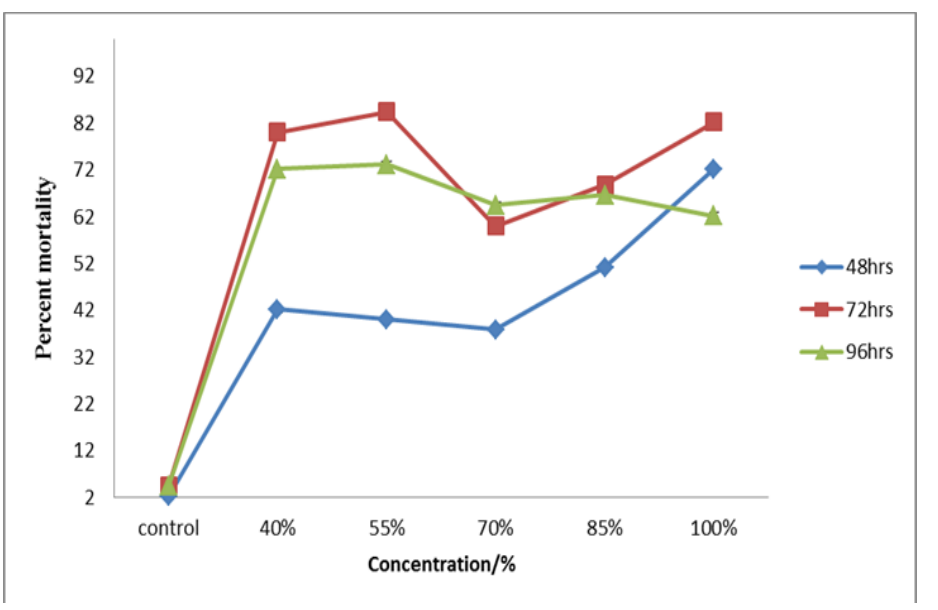

Figure 1. Effect of soaking period and concentration of false yam tuber extract on aphid mortality by topical application. $\operatorname{LSD}(p<0.05)=0.63$.

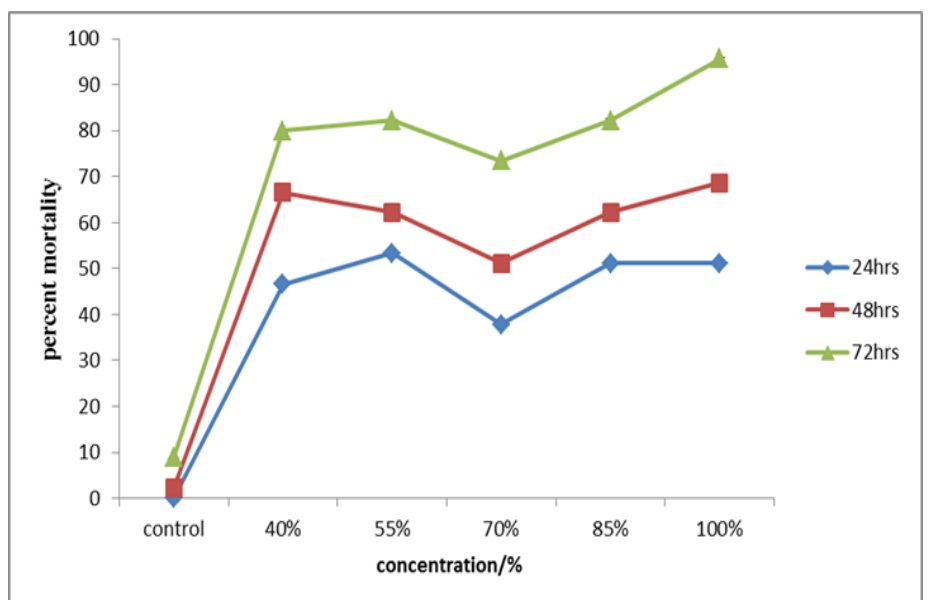

Figure 2. Effect of concentration of false yam tuber extract and period of exposure of aphids on mortality. LSD $(p<0.05)=$ 0.63 .

Effect of Concentration of False Yam Tuber Extract and Period of Exposure of Aphids on Mortality

The longer the exposure period of the different treatments on the aphids, the more toxic they were (Figure 2). The difference in mortality rate was statistically different $(p=0.01)$.

Effect of Concentration and Duration of Exposure on Aphid Mortality By Soaked Leaves

Aphid mortality was significantly affected at $p<0.05$ by concentration, soaking period and duration of exposure. Concentration-duration of exposure effect was also observed. The relative efficacy of the false yam tuber extract was significantly affected by soaking periods. Data showed that the concentration of the extract increased with increasing soaking period. Results showed significant differences with increasing concentration and duration of exposure at $p=0.028$. The highest mortality of aphids was recorded after 72 hours of exposure to the various treatment concentrations as shown in Figure 3.

\section{DISCUSSION}

The present study shows that high concentration of false yam tuber extract has a significant impact on aphid mortality. Aphid mortality increased with increasing concentration of false yam tuber extract.

The reduction in aphid numbers of the false yam treated plants was due to the antifeedant effect of the tuber extract which led to the starvation and the death of the aphids. According to Fay (1987), the false yam contains an active compound known as gum resin which makes it toxic. This might have been the major cause of the death of the aphids. However, the effects were not immediate since aphids were found actively moving on the leaves a few days after the treatment application. Radha (2013) reported similar incidence of the delay of the effect of neem kernel extract against cowpea aphids. The average aphid mortality increased with the increasing concentration and the duration of aphid exposure. However, extremely high concentrations may cause dryness to the leaves which might kill the plant at field conditions. The pre-trial experiment carried out showed that when high amount of undiluted false yam tuber extract was applied 


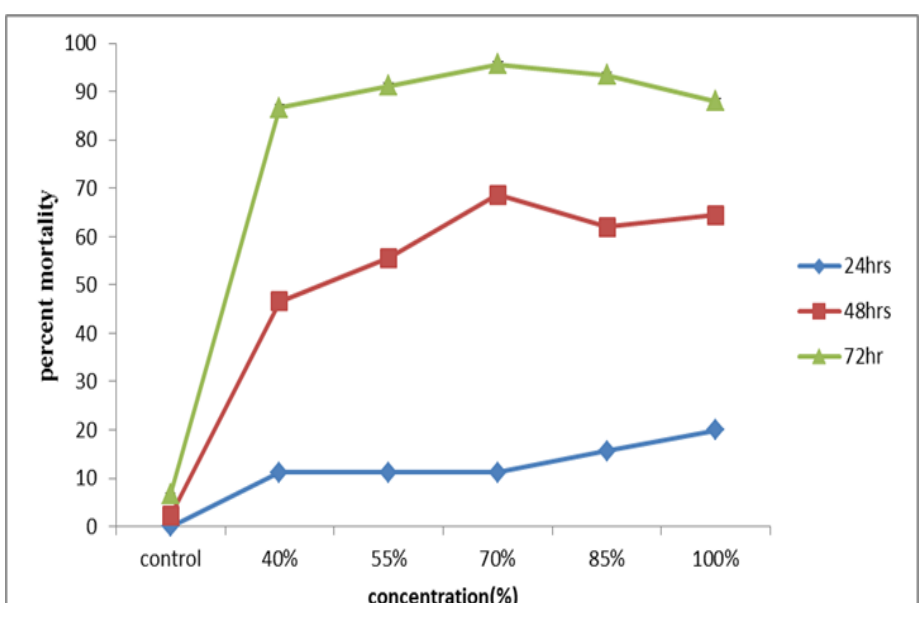

Figure 3. Effect of concentration of false yam and the duration of aphid exposure on mortality by indirect leaf spray $(p=0.028)$.

to the cowpea plant, the leaves dried up within 24 hours. The mean aphid mortalities were higher at $72 \mathrm{hrs}$ of exposure and at $55-85 \%$ of the false yam tuber extract mixed with their respective percentages of water.

Aphid mortality was significantly affected by the soaking period, concentration and duration of exposure. Vanhaelen et al., (1987) reported that the natural product of the false yam plant contains toxic compounds called terpenes that limit its utilization as food. The components of the compounds such as Icacenone, sitosterol 3-0-B-D-glucopyranoside and sigmasterol 3-0-B-D-glucopyranoside could act as insecticides (Vanhaelen et al., 1987).

Aphids have soft bodies that contain openings called spiracles used for respiration, delivering oxygen to the insect's body tissue (SF Gate, Home Guide, 2007). The ability of the extract to kill aphids when topically applied may be as a result of two reasons: either the extract is toxic resulting in direct death or indirectly by blocking the aphid's spiracles. SF Gate (2007) report in the control of A. craccivo$r a$ showed that insecticidal soap killed most aphids within one hour, suggesting suffocation as a cause of death. Insecticidal soaps and oils (petroleum-based horticultural oils or plant derived oils such as neem or canola oils) have best been used to kill aphids primarily by smothering (Flint, 2013). However, the effect of the false yam tuber extract was realized after $24 \mathrm{hrs}$ with increasing concentration, suggesting that aphid mortality was more likely to be due to the toxicity of the extract rather than suffocation. This results agrees with Flint (2013) who stated that insecticidal soaps, neem oils and horticultural oils kill aphids present on the day they are sprayed.

\section{CONCLUSION}

The present study demonstrated that aqueous extract from the false yam tuber has potential as an insecticide for cowpea black aphids. This study shows that the different concentrations of the aqueous $I$. oliviformis had significant effects on the cowpea aphids. The results obtained revealed the effectiveness of the tuber extract with increasing concentration and soaking period. They further suggested that $55 \%$ \& $70 \%$ concentrations of the false yam extracts proved effective after 72 hours soaking.

Among the trials to determine the plausible mode of action of the extract, toxicity by topical application and indirect leaf spray proved to be the effect mode of action. Toxicity and mortality of aphids were greatly influenced by both topical application and antifeeant test. The results obtained also revealed that the extract requires 72 hours after application for it to be effective as control mechanism on the target organism. This may explain why the extract was not effective in the field due to the frequent rains soon after the treatment applications.

\section{ACKNOWLEDGEMENT}

To the almighty God, to whom I really owe my thanks for making my dreams come true for this work would not have been realized. I might not have come this far without the outstanding support of Mr. Samuel Erasmus Afrane for funding this work. My greatest gratitude also goes to my project supervisor, Dr. Nelson Opoku. God bless you for your advice, direction, and motivation to undertake this great piece of work. To Dr. Charles Adarkwah, thank you for your immense contribution and ideas which helped to accomplish the objectives of this work. I would also like to thank Dr. Francis K. Amagloh for his help during my data analysis.

\section{REFERENCES}

Adarkwah, C., Obeng-Ofori, D., Büttner, C., Reichmuth, C., \& Schöller, M. (2010). Bio-rational Control of Red flour Beetle Tribolium Castaneum (Herbst) (Coleoptera: Tenebrionidae) In Stored Wheat with Calneem Oil Derived from Neem Seeds. J Pest Sci, 83(4), 471-479. doi: 10.5073/jka.2010.425.167.505.

Dei, H. K., Bacho, A., Adjeti, J., \& Rose, S. P. (2011). Nutritive Value of False Yam (Icacina Oliviformis) Tuber Meal for Broiler Chickens. Poultry Science, 90(6), 1239-1244. doi: 10.3382/ps.2010-01107.

Fay, J. M. (1987). Icacina oliviformis (Icacinaceae): A close look at unexploited crop. I. Overview and ethnobotany. Economic Botany, 41(4), 512-522. doi: 10.1007/BF02908146.

Flint, M. L. (2013). Pest Notes: Aphids. UC Statewide IPM Program and Entomology, UC Davis. Univ. Calif Agric. Nat. Res. Publ. 7404.

Ishiyaku, M. F., Higgins, T. J., Umar, M. L., Misari, S. M., Mignouna, H. J., Nang'Ayo, F., Stein, J., Murdock, L. M., Obokoh, M., \& Huesing, J. E. (2010). Field Evaluation of some transgenic Maruca Resistant Bt Cowpea for Agronomic traits under confinement in Zaria, Nigeria. Book of Abstracts of 5th World Cowpea Conference. Dakar, Senegal, 36-37.

Jackai, L. E., \& Daoust, R. A. (1986). Insect Pests of Cowpeas. Annual Review Of Entomology, 31(1), 95-119. doi: 10.1146/annurev.en.3110186.000523.

Leake, A. (2000). The Development of Integrated Crop Management in Agricultural Crops: Comparisons with Conventional Methods. J. of Pest Manag. Sci. 56(11), 950-953. doi: 10.1002/1526-4998(200011)56:11.

Ofuya, T. I. (1997). Studies on the capability of Cheilomenes Lunata (Fabricius) (Coleoptera: Coccinellidae) To Prey On the Cowpea Aphid, Aphis Craccivora Koch (Homoptera: Aphididae) in Nigeria. Agriculture, ecosystems \& environment, 52(1), 35-38. doi: 10.1016/0167-8809(94)09006-s.

Radha, R. (2013). Comparative Studies on the Effectiveness of Pesticides for Aphid Control In Cowpea. Research Journal of Agriculture and Forestry Science, 1(6), $1-7$.

SF Gate, Home Guide. (2007). Natural Control of Aphids on Roses. Retrieved from http://homeguides.sfgate.com/natural-control-aphids-roses-29990.html.

Shannag, H. S., Capinera, J. L., \& Freihat, N. M. (2014). Efficacy of Different Neem-Based Biopesticides against Green Peach Aphid, Myzus Persicae. International Journal of Agricultural Policy and Research, 2(2), 061068 . 